\title{
Does the level of reproductive knowledge specific to inflammatory bowel disease predict childlessness among women with inflammatory bowel disease?
}

\author{
Vivian W Huang MSc MD FRCPC ${ }^{1}$, Hsiu-Ju Chang MSc1, Karen I Kroeker MSc MD FRCPC ${ }^{1}$, Karen J Goodman PhD¹, \\ Kathleen M Hegadoren RN PhD², Levinus A Dieleman MD PhD ${ }^{1}$, Richard N Fedorak MD FRCPC
}

VW Huang, H Chang, KI Kroeker, et al. Does the level of reproductive knowledge specific to inflammatory bowel disease predict childlessness among women with inflammatory bowel disease? Can J Gastroenterol Hepatol 2015;29(2):95-103.

BACKGROUND: Women with inflammatory bowel disease (IBD) may choose to remain childless due to a lack of IBD-specific reproductive knowledge.

OBJECTIVES: To examine the effects of IBD-specific reproductive knowledge and discussion of family planning with a physician on childlessness among women with IBD.

METHODS: Female IBD patients 18 to 45 years of age completed the Crohn's and Colitis Pregnancy Knowledge questionnaire (CCPKnow), and answered questions regarding reproductive history, plans to have children and discussion of family planning with a physician. CCPKnow scores were grouped according to poor ( 0 to 7 ), adequate ( 8 to 10 ), good (11 to 13$)$ and very good (14 to 17 ).

RESULTS: Of 434 eligible women, 248 (57.1\%) completed the questionnaires. Of these 248 women, $51.6 \%$ were childless and, among these, $12.9 \%$ were voluntarily childless and $12.1 \%$ were trying to become pregnant. Childless women had a lower median CCPKnow score than women with children (6.0 versus $8.0 ; \mathrm{P}=0.001)$. After adjusting for current age and marital status, each one point increase in the CCPKnow score corresponded to $8 \%$ lower odds of childlessness (OR 0.92 [95\% CI 0.86 to 0.99]), 9\% lower odds of voluntary childlessness (OR 0.91 [95\% CI 0.79 to 1.0]) and 20\% higher odds of trying to become pregnant (OR 1.2 [95\% CI 1.0 to 1.4]). Discussion of family planning with a gastroenterologist corresponded to $72 \%$ lower odds of a poor CCPKnow score (OR 0.28 [95\% CI 0.15 to 0.53$]$ ) and of voluntary childlessness (OR 0.28 [95\% CI 0.057 to 1.3]).

CONCLUSION: In the present study, higher IBD-specific reproductive knowledge lowered the odds of childlessness among women with IBD. Discussion of family planning with a physician was associated with higher CCPKnow scores and lower odds of voluntary childlessness.

Key Words: Childlessness; Family planning; Inflammatory bowel disease; Patient knowledge; Physician knowledge

Inflammatory bowel disease (IBD) affects patients in their reproductive adult years. Management of IBD can, therefore, be challenging when integrating the effects of IBD and its treatment on fertility, pregnancy, breastfeeding, and maternal and neonatal outcomes. Women with IBD have been reported to have fewer children, with reported ranges of $14 \%$ to $36 \%$ of women with IBD choosing not to have children, a decision termed 'voluntary childlessness' (1-4), compared with reported ranges of $2.5 \%$ to $28 \%$ in the general population (3). Previous reports have documented that the reasons women with IBD choose voluntary childlessness include concerns related to medicationassociated teratogenicity $(2,3)$, the impact of pregnancy on their IBD (1), the risk of passing IBD to their child $(1,2)$ and not being able to care
Le niveau de connaissances sur la procréation en cas de maladie inflammatoire de l'intestin est-il prédictif de l'infécondité chez les femmes atteintes de cette maladie?

HISTORIQUE : Les femmes atteintes d'une maladie inflammatoire de l'intestin (MII) peuvent choisir de ne pas avoir d'enfants en raison d'un manque de connaissances sur la procréation en cas de MII.

OBJECTIFS : Examiner les effets des connaissances sur la procréation liée aux MII et des discussions sur la planification familiale avec un médecin au sujet de l'infécondité chez les femmes atteintes d'une MII.

MÉTHODOLOGIE : Des patientes atteintes d'une MII de 18 à 45 ans ont rempli le questionnaire CCPKnow sur les connaissances de la grossesse en cas de maladie de Crohn et de colite ulcéreuse et ont répondu à des questions sur les antécédents reproductifs, les projets d'avoir des enfants et les discussions sur la planification familiale avec un médecin. Les scores du CCPKnow étaient classés comme mauvais ( 0 à 7 ), adéquats ( 8 à 10$)$, bons (11 à 13) et très bons (14 à 17).

RÉSULTATS : Sur 434 femmes admissibles, 248 (57,1 \%) ont rempli le questionnaire. De ce nombre, 51,6 \% n'avaient pas d'enfants, dont 12,9\% avaient fait ce choix volontairement et $12,1 \%$ tentaient d'en avoir. Les femmes sans enfants présentaient un score CCPKnow médian plus faible que celles qui en avaient $(6,0$ par rapport à 8,$0 ; \mathrm{P}=0,001)$. Après rajustement compte tenu de l'âge et de la situation conjugale, chaque augmentation d'un point au score CCPKnow correspondait à une diminution de $8 \%$ de la probabilité de ne pas avoir d'enfant (RC 0,92 [95 \% IC 0,86 à 0,99]), à une diminution de $9 \%$ de la décision volontaire ne pas en avoir (RC $0,91[95 \%$ IC 0,79 à 1,0$]$ ) et à une augmentation de $20 \%$ de la probabilité d'essayer d'avoir un enfant (RC 1,2 [95 \% IC 1,0 à 1,4]). Des discussions sur la planification familiale avec un gastroentérologue entraînaient une diminution de $72 \%$ de la probabilité d'obtenir un mauvais score CCPKnow (RC 0,28 [95\% IC 0,15 à 0,53]) et de décider volontairement ne pas avoir d'enfant (RC 0,28 [95 \% IC 0,057 à 1,3]).

CONCLUSION : Dans la présente étude, de meilleures connaissances sur la procréation liée aux MII réduisait la possibilité de ne pas avoir d'enfant chez les femmes atteintes d'une MII. Les discussions sur la planification familiale avec un médecin s'associaient à des scores CCPKnow plus élevés et à une plus faible probabilité de décider volontairement de ne pas avoir d'enfants.

for their child (1). However, many of these concerns are unsubstantiated because women with IBD, in general, have similar fertility to the general population, and are able to carry successful pregnancies and care for their infants, especially if their IBD is in remission (5-11).

Several studies have reported deficits in IBD-specific reproductive knowledge among women with IBD and investigators have postulated that voluntary childlessness is due to lack of knowledge $(2,4,12,13)$. However, the association between IBD-specific reproductive knowledge and childlessness among women with IBD is not well characterized. Current age and marital status may influence a woman's decision regarding having children; these variables have not been studied previously with respect to IBD-specific reproductive knowledge and

${ }^{1}$ Division of Gastroenterology, Faculty of Medicine; ${ }^{2}$ Faculty of Nursing, University of Alberta, Edmonton, Alberta

Correspondence: Dr Vivian W Huang, 130 University Campus, Zeidler Ledcor Centre, Edmonton, Alberta T6G 2 X8.

Telephone 780-248-1031, fax 780-248-1041, e-mail vwhuang@ualberta.ca

Received for publication October 2, 2014. Accepted December 2, 2014 
childlessness, including voluntary childlessness. IBD-specific reproductive knowledge may also influence whether a childless woman tries to become pregnant, a behaviour that reveals whether childlessness is voluntary. The association between knowledge and trying to become pregnant has not previously been examined among women with IBD. In addition, there has also been little exploration of the association of physician-patient discussion of family planning with knowledge and childlessness among patients.

The primary objective of the present study was to examine the effect of IBD-specific reproductive knowledge level (adjusted for age and marital status) on childlessness, including but not limited to voluntary childlessness, among women with IBD. The secondary objectives were to examine the effects of family planning discussion with a physician on IBD-specific reproductive knowledge among women with IBD and voluntary childlessness among childless women with IBD.

\section{METHODS}

\section{Study design}

A cross-sectional survey of women with IBD was designed to assess their knowledge of IBD-specific reproductive issues and to assess their plans with regard to having children.

\section{Setting and participants}

The study was conducted at the Inflammatory Bowel Disease Consultation and Research Clinic at the University of Alberta Hospital (Edmonton, Alberta). An electronic health records database was used to systematically identify all female patients with IBD (Crohn disease, ulcerative colitis, indeterminate colitis) 18 to 45 years of age who attended the clinic between January 2010 and June 2013. The years for inclusion criteria for clinic attendance were selected to reflect the most recent interaction between patient and physician. There were no predetermined exclusion criteria in terms of IBD type, medications or reproductive history.

A package of printed material consisting of an information and consent form, the study questionnaires and a stamped, postage-paid return envelope was either mailed to the home address on file or handed directly to patients during a clinic visit. Patients who had not returned the self-administered questionnaire and survey within three months were sent either a reminder by mail or, if an e-mail address was available, by e-mail with a link to an Internet-based version of the questionnaire. A second reminder via telephone occurred approximately three months after the first reminder. The number of eligible women identified from the electronic database and the subsequent response rate determined the sample size for the present study.

\section{Data sources and variable definitions}

Crohn's and Colitis Pregnancy Knowledge score: The tool used to measure IBD-specific reproductive knowledge was the Crohn's and Colitis Pregnancy Knowledge survey (CCPKnow) (14). CCPKnow scores, calculated by summing the correct responses to each question, range from 0 to 17 , and respondents were categorized into poor ( 0 to 7 ), adequate (8 to 10$)$, good (11 to 13 ) and very good (14 to 17 ) CCPKnow knowledge levels.

Reproductive history: history of pregnancy and childlessness: Women were divided into categories according to history of pregnancy: ever pregnant or never been pregnant; and according to history of having biological children: childless (no live births, adopted children only); or have children. Women who had adopted children only were included in the childless group, and women who had both biological and adopted children were included in the have children group because many of the knowledge topic target issues relating to the physiology of not only carrying a biological pregnancy, but also of delivery, postpartum and breastfeeding.

Family planning decisions: voluntary childlessness and trying to become pregnant: Women were asked about their current plans to have children with response options: do not want to have children; would like adopted children only; trying to become pregnant; have children, would like more; have children, completed family; do not have children, would like to later on; and unsure. Childless women were subcategorized as having voluntary childlessness if they were childless at the time of the survey and if they had selected 'do not want to have children' or 'would like adopted children only'. Childless women were also categorized as 'trying to become pregnant' if they were childless at the time of study completion and if they selected the response 'trying to become pregnant'.

\section{Other study variables}

The classification of subjects as having discussed family planning with a physician was based on responses to the question "who have you discussed family planning with?", with response options being: Gastroenterologist; General medicine specialist; Obstetrician; Family physician; IBD nurse; Pharmacist; Family and friends; Other; or Have not discussed with anyone. The questionnaire also asked patients questions regarding demographics, factors that could affect knowledge, fertility and pregnancy, IBD history, and reproductive history and current family planning status.

Exposure (independent) variables and outcome (dependent) variables: To estimate the effects of IBD-specific reproductive knowledge on childlessness, the CCPKnow score was analyzed as the exposure variable, with childlessness as the outcome variable. To estimate the effects of discussion of family planning on IBD-specific reproductive knowledge and voluntary childlessness, discussion of family planning was analyzed as the exposure variable, with CCPKnow score and voluntary childlessness as the outcome variables.

\section{Methods used to reduce bias}

To minimize selection bias, all eligible patients in the database were systematically invited to participate and multiple attempts were made to reach each patient. Using detailed questions to accurately classify reproductive history, family planning status and intentions with respect to having children minimized measurement bias. In addition, a standard measure of IBD-specific reproductive knowledge was obtained through the CCPKnow survey.

\section{Statistical methods}

The present analysis aimed to estimate the effects of IBD-specific reproductive knowledge on childlessness in two ways: by comparing the median CCPKnow scores of childless women to women with children; and by estimating ORs for the dose-response association between the CCPKnow score in one point increments and childlessness. The analysis aimed additionally to estimate the effects of having discussed family planning on IBD-specific reproductive knowledge and voluntary childlessness.

For CCPKnow scores and other continuous variables, medians and interquartile ranges (IQRs) were calculated, and medians were compared across subgroups using nonparametric Mann-Whitney and Kruskall-Wallis tests. For categorical variables, frequency distributions of categories were tabulated and differences in distributions were compared across subgroups. The statistical hypothesis that the distributions did not differ was tested using the $\chi^{2}$ test. P-values for the null hypothesis of no difference are reported for the comparison of medians and frequency distributions.

When analyzed as an outcome variable, IBD-specific reproductive knowledge was dichotomized as poor versus adequate/good/very good based on the CCPKnow score. To estimate the effect of independent variables on either childlessness or poor CCPKnow scores, multivariable logistic regression was used to obtain ORs and 95\% CIs adjusted for selected covariates. Covariates were selected based on whether they could affect both the independent variable of interest and the outcome of interest, without being affected by the independent variable. The resulting multivariable models were repeated with stratification according to age and marital status because the prevalence of childlessness was lower among older women and among married women. SPSS version 21.0 (IBM Corporation, USA) for Windows 2012 (Microsoft Coporation, USA) was used for all data analysis. 
TABLE 1

Prevalence of childlessness according to selected study variables among $\mathbf{2 4 8}$ female inflammatory bowel disease (IBD) patients*

\begin{tabular}{|c|c|c|c|}
\hline & $\begin{array}{l}\text { Total patients } \\
(\mathrm{n}=248)\end{array}$ & $\begin{array}{l}\text { Prevalence of } \\
\text { childlessness }\end{array}$ & \\
\hline Category & n (\% of total) & $\mathrm{n} / \mathrm{n}$ (\% of category) & ) $P\left(x^{2}\right)$ \\
\hline \multicolumn{4}{|l|}{ Current age, years } \\
\hline 18 to 24 & $49(19.8)$ & $47 / 49$ (95.9) & $<0.001$ \\
\hline 25 to 29 & $50(20.2)$ & $34 / 50(68.0)$ & \\
\hline 30 to 34 & $56(22.6)$ & $24 / 56(42.9)$ & \\
\hline 35 to 39 & $47(19.0)$ & $12 / 47(25.5)$ & \\
\hline 40 to 45 & $46(18.5)$ & $11 / 46(23.9)$ & \\
\hline \multicolumn{4}{|l|}{ Marital status } \\
\hline Partnered & $173(69.8)$ & $66 / 173(38.2)$ & $<0.001$ \\
\hline Divorced & $8(3.2)$ & $2 / 8(25.0)$ & \\
\hline Single & $67(27.0)$ & 60/67 (89.6) & \\
\hline \multicolumn{4}{|l|}{ Ethnicity $(n=230)^{\dagger}$} \\
\hline Caucasian & $216(93.9)$ & $118 / 216(54.6)$ & 0.39 \\
\hline Non-Caucasian & $14(6.1)$ & $6 / 14(42.9)$ & \\
\hline \multicolumn{4}{|l|}{ Education } \\
\hline Grade 1 to grade 12 & $56(22.6)$ & $29 / 56(51.8)$ & 0.26 \\
\hline College/university & $157(63.3)$ & $76 / 157(48.4)$ & \\
\hline Graduate degree & $11(4.4)$ & $7 / 11(63.6)$ & \\
\hline Professional school degree & $5(2.0)$ & $2 / 5(40.0)$ & \\
\hline Other & $19(7.7)$ & $14 / 19(73.7)$ & \\
\hline \multicolumn{4}{|l|}{ Employment $(n=229)^{\dagger}$} \\
\hline Unemployed & $28(12.2)$ & $13 / 28(46.4)$ & 0.02 \\
\hline Part-time & $46(20.1)$ & $24 / 46(52.2)$ & \\
\hline Full-time & $117(51.1)$ & $73 / 117(62.4)$ & \\
\hline Other & $38(16.6)$ & $13 / 38(34.2)$ & \\
\hline \multicolumn{4}{|l|}{ Family history of IBD } \\
\hline Yes & $107(43.1)$ & $52 / 107(48.6)$ & 0.41 \\
\hline No & $141(56.9)$ & $76 / 141(53.9)$ & \\
\hline \multicolumn{4}{|l|}{ History of pregnancy } \\
\hline Yes & $136(54.8)$ & $17 / 136(12.5)$ & $<0.001$ \\
\hline No & $112(45.2)$ & $111 / 112(99.7)$ & \\
\hline \multicolumn{4}{|c|}{ Timing of pregnancy in relation to IBD diagnosis $(n=135)^{\dagger}$} \\
\hline Before only & $36(26.7)$ & $4 / 36(11.1)$ & 0.50 \\
\hline After only & $78(57.8)$ & $11 / 78(14.1)$ & \\
\hline Before and after & $21(15.6)$ & $1 / 21(4.8)$ & \\
\hline \multicolumn{4}{|l|}{ Type of IBD } \\
\hline Crohn disease & $150(60.5)$ & $76 / 150(50.7)$ & 0.49 \\
\hline Ulcerative colitis & $88(35.5)$ & $45 / 88(51.1)$ & \\
\hline Indeterminate & $10(4.0)$ & $7 / 10(70.0)$ & \\
\hline \multicolumn{4}{|l|}{ Age at IBD diagnosis, years } \\
\hline$<18$ & $65(26.2)$ & $49 / 65(75.4)$ & $<0.001$ \\
\hline$\geq 18$ & $183(73.8)$ & $79 / 183(43.2)$ & \\
\hline \multicolumn{4}{|l|}{ Duration of IBD, years } \\
\hline 0 to 5 & $57(23.0)$ & $33 / 57(57.9)$ & 0.28 \\
\hline$\geq 5$ & $191(77.0)$ & 95/191 (49.7) & \\
\hline \multicolumn{4}{|l|}{ History of medications for IBD } \\
\hline \multicolumn{4}{|c|}{ 5-aminosalicylates/sulfasalazine } \\
\hline Yes & $218(87.9)$ & $113 / 218(51.8)$ & 0.85 \\
\hline No & $30(12.1)$ & $15 / 30(50.0)$ & \\
\hline \multicolumn{4}{|l|}{ Steroids } \\
\hline Yes & $216(87.1)$ & $114 / 216(52.8)$ & 0.34 \\
\hline No & $32(12.9)$ & $14 / 32(43.8)$ & \\
\hline & & Continued in & xt column \\
\hline
\end{tabular}

TABLE 1 - CONTINUED

\begin{tabular}{|c|c|c|c|}
\hline \multicolumn{4}{|c|}{$\begin{array}{l}\text { Prevalence of childlessness according to selected study } \\
\text { variables among } 248 \text { female inflammatory bowel disease } \\
\text { (IBD) patients* }\end{array}$} \\
\hline \multirow[b]{2}{*}{ Category } & $\begin{array}{l}\text { Total patients } \\
(n=248)\end{array}$ & $\begin{array}{l}\text { Prevalence of } \\
\text { childlessness }\end{array}$ & \multirow[b]{2}{*}{$P\left(x^{2}\right)$} \\
\hline & $\mathrm{n}$ (\% of total) & $\overline{n / n}$ (\% of category) & \\
\hline \multicolumn{4}{|l|}{ Methotrexate } \\
\hline Yes & $42(16.9)$ & $19 / 42(45.2)$ & \multirow[t]{2}{*}{0.36} \\
\hline No & $206(83.1)$ & 109/206 (52.9) & \\
\hline \multicolumn{4}{|c|}{ Azathioprine/6-mercaptopurine } \\
\hline Yes & $180(72.6)$ & $97 / 180(53.9)$ & \multirow[t]{2}{*}{0.24} \\
\hline No & $68(27.4)$ & $31 / 68(45.6)$ & \\
\hline \multicolumn{4}{|c|}{ Biologics (infliximab, adalimumab) } \\
\hline Yes & $117(47.2)$ & $62 / 117(53.0)$ & \multirow[t]{2}{*}{0.68} \\
\hline No & $131(52.8)$ & $66 / 131(50.4)$ & \\
\hline \multicolumn{4}{|l|}{ History of surgery for IBD } \\
\hline \multicolumn{4}{|l|}{ Ostomy } \\
\hline Yes & $24(9.7)$ & $18 / 24(75.0)$ & \multirow[t]{2}{*}{0.016} \\
\hline No & $224(90.3)$ & $110 / 224(49.1)$ & \\
\hline \multicolumn{4}{|l|}{ Colectomy } \\
\hline Yes & $17(6.9)$ & $13 / 17(76.5)$ & \multirow[t]{2}{*}{0.034} \\
\hline No & $231(93.1)$ & $115 / 231(49.8)$ & \\
\hline \multicolumn{4}{|l|}{ History of perianal disease } \\
\hline Yes & $54(24.0)$ & 29/54 (53.7) & \multirow[t]{2}{*}{0.99} \\
\hline No & $92(76.0)$ & $92 / 171(53.8)$ & \\
\hline \multicolumn{4}{|c|}{ Have discussed family planning with a physician } \\
\hline Yes & $154(62.1)$ & $72 / 154(46.8)$ & \multirow[t]{2}{*}{0.050} \\
\hline No & $94(37.9)$ & $56 / 94(59.6)$ & \\
\hline \multicolumn{4}{|c|}{ Have discussed family planning with a gastroenterologist } \\
\hline Did not discuss & $94(37.9)$ & $56 / 94(59.6)$ & \multirow[t]{3}{*}{0.016} \\
\hline Gastroenterologist & $105(42.3)$ & $43 / 105(41.0)$ & \\
\hline Nongastroenterologist & $49(19.8)$ & $29 / 49(59.2)$ & \\
\hline \multicolumn{4}{|l|}{ CCPKnow level } \\
\hline Poor (0 to 7$)$ & $131(52.8)$ & $78 / 131(59.4)$ & \multirow[t]{4}{*}{0.070} \\
\hline Adequate (8 to 10$)$ & $49(19.8)$ & $21 / 49(42.9)$ & \\
\hline Good (11 to 13$)$ & $48(19.4)$ & $21 / 48(43.8)$ & \\
\hline Very good (14 to 17$)$ & $20(8.1)$ & $8 / 20(40.0)$ & \\
\hline \multicolumn{4}{|c|}{ CCPKnow level - dichotomized } \\
\hline Poor (0 to 7$)$ & $131(52.8)$ & 78/131 (59.4) & \multirow[t]{2}{*}{0.008} \\
\hline Adequate $(\geq 8)$ & $117(47.2)$ & $50 / 117(42.7)$ & \\
\hline
\end{tabular}

${ }^{*}$ From the IBD Consultation and Research Clinic, University of Alberta Hospital (Edmonton, Alberta), 2010 to 2013; †Percentages calculated using the total number of patients with responses as the denominator. CCPKnow Crohn's and Colitis Pregnancy Knowledge survey

Ethical considerations

The present study and the study materials were approved by the Health Research Ethics Board of the University of Alberta. Patients were informed that participation in the study was voluntary. Paper study materials included wet-ink signed consent forms while electronic study materials included an electronic consent form. Patients received a \$10 coffee gift card on return of the completed study materials.

Participants

\section{RESULTS}

Of the 434 eligible women with IBD in the clinic database, 252 of $434(58.1 \%)$ completed the questionnaire. Four incomplete questionnaires were excluded, yielding 248 of 434 (57.1\% response rate) evaluable subjects, with their demographic data summarized in Table 1 . The median age was 32.0 years (IQR 26.0 to 38.0 years), with $69.8 \%$ (173 of 248) of the respondents indicating they had a partner (married/in a long-term relationship). Crohn disease was present in 60.5\% (150 of 


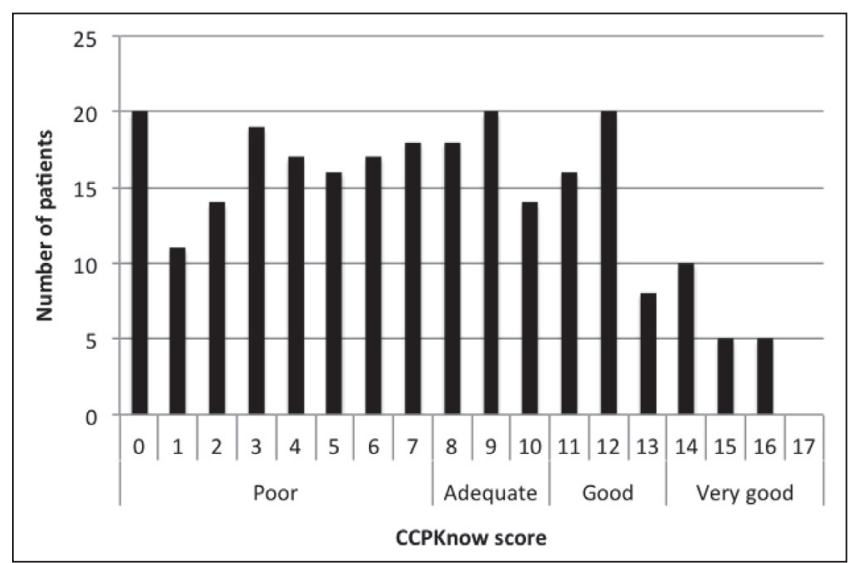

Figure 1) Distribution of Crohn's and Colitis Pregnancy Knowledge survey (CCPKnow) scores measuring inflammatory bowel disease (IBD)specific reproductive knowledge among 248 female IBD patients from the IBD Consultation and Research Clinic, University of Alberta Hospital (Edmonton, Aberta), 2010 to 2013 ( $n=248)$. Poor $n=131 / 248$ (52.8\%); Adequate $n=49 / 248$ (19.8\%); Good $n=48 / 248$ (19.4\%); Very good $n=20 / 248(8.1 \%)$

248), ulcerative colitis in $35.0 \%$ (88 of 248) and indeterminate colitis in $4.0 \%$ (10 of 248) of the respondents. The median age at diagnosis was 21.0 years (IQR 17.0 to 27.0 years) and the median duration of disease was 9.0 years (IQR 5.0 to 15.0 years).

Reproductive history: pregnancy history and childlessness, voluntary childlessness and trying to become pregnant

Slightly more than one-half (128 of 248 [51.6\%]) of the women were childless. Seven women indicated they had adopted children, of whom three had both adopted and biological children, and four had adopted children only. Only one of these four women had ever been pregnant (she underwent a therapeutic abortion). The prevalence of childlessness among each category examined is shown in Table 1 . The prevalence of childlessness was higher among patients who were diagnosed with IBD before 18 years of age $(\mathrm{P}<0.001)$, had a history of ostomy $(\mathrm{P}<0.016)$ or colectomy $(\mathrm{P}=0.034)$, and among those working full-time $(\mathrm{P}=0.02)$, those with poor CCPKnow scores $(\mathrm{P}=0.008)$ and those without partners $(\mathrm{P}=0.001)$.

Among the 128 childless women, 14 (10.9\%) indicated they had ever sought a fertility specialist or had undergone fertility treatment. There was little difference between women who had children and childless women in the proportion who had sought a fertility specialist or fertility treatment (14 of 120 [11.7\%] versus 14 of 128 [10.9\%]; $\mathrm{P}=0.86$ ).

Seventeen of the 128 childless women indicated they had ever been pregnant, with a total of 22 pregnancies. Five (29.4\%) of these 17 women had been pregnant only before they were diagnosed with IBD, $11(64.7 \%)$ only after they were diagnosed with IBD, and one $(5.9 \%)$ both before and after being diagnosed with IBD; 13 of these $17(76.5 \%)$ women experienced miscarriage/stillbirth/spontaneous abortions and nine $(52.9 \%)$ underwent therapeutic abortions.

Of the 128 childless women, 116 answered the question about their current plans to have children. Of these 116 childless women, 15 (12.9\%) were categorized as having voluntary childlessness and 14 (12.1\%) were categorized as trying to become pregnant.

The 15 voluntarily childless women had an older median age than the remainder of the childless women (36.0 years [IQR 30.0 to 45.0 years versus 26.0 years [IQR 22.0 to 32.0 years]; $\mathrm{P}=0.001$ ). They were diagnosed at an older median age (22.0 years [IQR 20.0 to 26.0 years] versus 18.0 years [IQR 15.0 to 22.0 years]; $\mathrm{P}=0.007$ ), and had a longer median duration of disease (13.0 years [IQR 6.0 to 20.0 years] versus 8.0 years [IQR 5.0 to 12.0 years]; $\mathrm{P}=0.032$ ). There were no clear differences in disease type or disease characteristics (perianal disease, ostomy, colectomy) compared with other childless women. Three of these $15(20.0 \%)$ women had ever been pregnant; all three underwent therapeutic abortions.

The 14 childless women who were trying to become pregnant had an older median age than the remainder of the childless women (34.0 years [IQR 31.0 to 37.0 years] versus 26.0 years [IQR 21.0 to 32.0 years]; $\mathrm{P}<0.001)$. Their median age at diagnosis was similar to that of the remainder of the childless women (19.0 years [IQR 17.0 to 28.0 years] versus 19.0 years [IQR 15.0 to 22.0 years]; $P=0.19$ ). There were no clear differences in disease type or disease characteristics (perianal disease, ostomy, colectomy) compared with other childless women. Four $(28.6 \%)$ women had ever been pregnant, all of whom experienced miscarriages.

\section{CCPKnow scores}

Figure 1 illustrates the distribution of CCPKnow scores. The median CCPKnow score was 7.0 (IQR 3.0 to 11.0 ), with more than one-half (131 of 248 [52.8\%]) of the women having poor CCPKnow scores. Table 2 shows the median CCPKnow scores and the proportion with poor CCPKnow scores among women in each category. The median CCPKnow score was 4.0 points higher among women who had ever been pregnant $(\mathrm{P}<0.001), 2.0$ points higher among women who had children $(P<0.001)$ and 4.0 points higher among women who had discussed family planning with a physician $(\mathrm{P}<0.001)$.

The association of IBD-specific reproductive knowledge level with childlessness, voluntary childlessness and trying to become pregnant As shown in Table 1, the prevalence of childlessness was $16.8 \%$ higher among women with poor CCPKnow scores than among women with adequate or higher CCPKnow scores (78 of 131 [59.5\%] versus 50 of 117 [42.7\%], respectively; $\mathrm{P}=0.008)$. As shown in Table 2, childless women had a median CCPKnow score that was 2.0 points lower than the median CCPKnow score of women with children (6.0 [IQR 3.0 to 9.0] versus 8.0 [IQR 5.0 to 11.0 ], respectively; $\mathrm{P}=0.001$ ). As shown in Table 3, multivariable logistic regression estimated an OR adjusted for current age and marital status of 0.92 (95\% CI 0.86 to 0.99 ) for the effect of IBD-specific reproductive knowledge on childlessness; thus, every one point increase in the CCPKnow score corresponded to an $8 \%$ lower odds of childlessness.

Given that there were large differences in the prevalence of childlessness across groups defined according to age and marital status, the logistic regression model was repeated within strata of age and marital status. Table 3 shows that the observed inverse association between the CCPKnow score and childlessness was strongest among women $\leq 34$ years of age who were partnered; in contrast, the CCPKnow score was not clearly associated with childlessness in single women $\leq 34$ years of age or in older women with partners (there were too few single women $>34$ years of age to examine this relationship in this group).

Compared with the nonvoluntarily childless women, the 15 voluntarily childless women had a similar median CCPKnow score (4.0 [IQR 2.0 to 10.0 ] versus 6.0 [IQR 3.0 to 9.0]; $\mathrm{P}=0.985)$ and a similar prevalence of poor CCPKnow scores (10 of 15 [66.7\%] versus 60 of 101 [59.4\%]; $\mathrm{P}=0.592$ ) (Table 2). Multivariable logistic regression estimated an OR adjusted for current age in years and marital status of 0.91 (95\% CI 0.79 to 1.0) for the effect of CCPKnow score on voluntary childlessness among childless women; thus, every one point increase in the CCPKnow score corresponded to $9 \%$ lower odds of voluntary childlessness among childless women (Table 4).

Compared with the childless women who were not trying to become pregnant, the 14 childless women who were trying to become pregnant had a higher median CCPKnow score (10.0 [IQR 9.0 to 12.0] versus 5.0 [IQR 2.0 to 9.0]; $\mathrm{P}=0.001)$ and a lower prevalence of poor CCPKnow scores (three of 14 [21.4\%] versus 67 of 102 [65.7\%]; $\mathrm{P}=0.002$ ) (Table 2). As shown in Table 4, multivariable logistic regression estimated an OR adjusted for current age in years and marital status of 1.2 (95\% CI 1.0 to 1.4) for the effect of CCPKnow on trying to become pregnant; thus, every one point increase in CCPKnow score corresponded to $20 \%$ higher odds of trying to become pregnant among childless women. 
TABLE 2

Description of inflammatory bowel disease (IBD)-specific reproductive knowledge levels in 248 female IBD patients*

\begin{tabular}{|c|c|c|c|c|}
\hline Category & $\begin{array}{c}\text { CCPKnow score, } \\
\text { median (IQR) }\end{array}$ & $\mathbf{P}^{\dagger}$ & $\begin{array}{c}\text { Poor CCPKnow } \\
\text { score } \\
n / n(\%)\end{array}$ & $\mathbf{P}^{\ddagger}$ \\
\hline Total $(n=248)$ & $7.0(3.0-11.0)$ & - & $131 / 248(52.8)$ & - \\
\hline \multicolumn{5}{|l|}{ Age, years } \\
\hline 18 to 24 & $4.0(2.0-8.0)$ & 0.001 & $34 / 49(69.4)$ & 0.04 \\
\hline 25 to 29 & $8.0(4.0-12.0)$ & & $23 / 50(46.0)$ & \\
\hline 30 to 34 & $9.0(6.0-12.0)$ & & 23/56 (41.1) & \\
\hline 35 to 39 & $6.0(3.0-9.0)$ & & $27 / 47(57.4)$ & \\
\hline 40 to 45 & $7.0(4.0-11.0)$ & & $24 / 46(52.2)$ & \\
\hline \multicolumn{5}{|l|}{ Marital status } \\
\hline Partnered & $8.0(4.0-11.0)$ & $<0.001$ & $75 / 173(43.4)$ & $<0.001$ \\
\hline Divorced & $8.0(5.0-10.0)$ & & $4 / 8(50.0)$ & \\
\hline Single & $5.0(2.0-7.0)$ & & $52 / 67(77.6)$ & \\
\hline \multicolumn{5}{|l|}{ Ethnicity } \\
\hline Caucasian & $7.0(3.0-11.0)$ & 0.498 & $113 / 216$ & 0.384 \\
\hline Non-Caucasian & $5.0(4.0-11.0)$ & & $9 / 14(64.3)$ & \\
\hline \multicolumn{5}{|l|}{ Education status } \\
\hline Grade 1 to grade 12 & $4.0(2.0-8.0)$ & 0.004 & 39/56 (69.6) & 0.007 \\
\hline College/university & $8.0(4.0-11.0)$ & & $79 / 157$ (50.3) & \\
\hline Graduate degree & $9.0(8.0-11.0)$ & & 2/11 (18.2) & \\
\hline Professional degree & $9.0(8.0-14.0)$ & & $1 / 5(20.0)$ & \\
\hline Other & $7.0(5.0-10.0)$ & & $10 / 19(52.6)$ & \\
\hline \multicolumn{5}{|l|}{ Employment status } \\
\hline Unemployed & $6.0(3.0-9.0)$ & 0.38 & $18 / 28(64.3)$ & 0.47 \\
\hline Part-time & $8.0(3.0-12.0)$ & & $21 / 46(45.7)$ & \\
\hline Full-time & $7.0(4.0-11.0)$ & & $61 / 117(52.1)$ & \\
\hline Other & $7.0(4.0-10.0)$ & & $21 / 38(55.3)$ & \\
\hline \multicolumn{5}{|l|}{ Family history of IBD } \\
\hline Yes & $8.0(4.0-11.0)$ & 0.39 & $54 / 107(50.5)$ & 0.52 \\
\hline No & $7.0(3.0-11.0)$ & & 77/141 (54.6) & \\
\hline \multicolumn{5}{|l|}{ Type of IBD } \\
\hline Crohn's disease & $7.0(4.0-11.0)$ & 0.37 & $77 / 150(51.3)$ & 0.51 \\
\hline Ulcerative colitis & $7.0(4.0-11.0)$ & & $47 / 88(53.4)$ & \\
\hline Indeterminate & $3.0(1.0-10.0)$ & & $7 / 10(70.0)$ & \\
\hline \multicolumn{5}{|c|}{ Age at IBD diagnosis, years } \\
\hline$<18$ & $6.0(3.0-9.0)$ & 0.027 & $40 / 65(61.5)$ & 0.10 \\
\hline$\geq 18$ & $7.0(4.0-11.0)$ & & $91 / 183(49.7)$ & \\
\hline \multicolumn{5}{|l|}{ Duration of IBD, years } \\
\hline$<5$ & $6.0(3.0-10.0)$ & 0.218 & $34 / 57(59.6)$ & 0.24 \\
\hline$\geq 5$ & $7.0(4.0-11.0)$ & & $97 / 191(50.8)$ & \\
\hline \multicolumn{5}{|l|}{ History of pregnancy } \\
\hline No & $6.0(3.0-9.0)$ & $<0.001$ & $70 / 112(62.5)$ & 0.006 \\
\hline Yes & $8.0(5.0-11.0)$ & & $61 / 136(44.9)$ & \\
\hline \multicolumn{5}{|c|}{ Timing of pregnancy in relation to IBD diagnosis $(n=135)$} \\
\hline Before only & $5.0(2.0-8.0)$ & 0.001 & 23/36 (63.9) & 0.011 \\
\hline After only & $10.0(7.0-12.0)$ & & $27 / 78(34.6)$ & \\
\hline Before and after & $7.0(4.0-10.0)$ & & $11 / 21(52.4)$ & \\
\hline \multicolumn{5}{|l|}{ Have children } \\
\hline No & $6.0(3.0-9.0)$ & $<0.001$ & $78 / 128$ (60.9) & 0.008 \\
\hline Yes & $8.0(5.0-11.0)$ & & $53 / 120(44.2)$ & \\
\hline \multicolumn{5}{|l|}{ Voluntary childlessness } \\
\hline No & $6.0(3.0-9.0)$ & 0.985 & 60/101 (59.4) & 0.592 \\
\hline Yes & $4.0(2.0-10.0)$ & & $10 / 15(66.7)$ & \\
\hline
\end{tabular}

TABLE 2 - CONTINUED

Description of inflammatory bowel disease (IBD)-specific reproductive knowledge levels in 248 female IBD patients*

\begin{tabular}{|c|c|c|c|c|}
\hline Category & $\begin{array}{c}\text { CCPKnow score } \\
\text { median (IQR) }\end{array}$ & $\mathbf{p}^{\dagger}$ & $\begin{array}{c}\text { Poor CCPKnow } \\
\text { score } \\
\end{array}$ & $\mathbf{P} \ddagger$ \\
\hline \multicolumn{5}{|c|}{ Childless and trying to become pregnant } \\
\hline No & $5.0(2.0-9.0)$ & 0.002 & $67 / 102(65.7)$ & 0.002 \\
\hline Yes & $10.0(9.0-12.0)$ & & $3 / 14(21.4)$ & \\
\hline \multicolumn{5}{|c|}{ Discussed family planning with a physician } \\
\hline Yes & $8.0(5.0-11.0)$ & $<0.001$ & $66 / 154$ (42.9) & $<0.001$ \\
\hline No & $4.0(2.0-8.0)$ & & $65 / 94(69.1)$ & \\
\hline \multicolumn{5}{|c|}{ Have discussed family planning with a gastroenterologist } \\
\hline Did not discuss & $4.0(2.0-8.0)$ & $<0.001$ & $65 / 94(69.1)$ & $<0.001$ \\
\hline Gastroenterologist & $9.0(7.0-12.0)$ & & $34 / 105(32.4)$ & \\
\hline $\begin{array}{l}\text { Non- } \\
\text { gastroenterologist }\end{array}$ & $6.0(3.0-9.0)$ & & $32 / 49(65.3)$ & \\
\hline
\end{tabular}

*Median Crohn's and Colitis Pregnancy Knowledge survey (CCPKnow) score and the proportion with a poor CCPKnow score according to selected study variables, IBD Consultation and Research Clinic, University of Alberta Hospital (Edmonton, Alberta), 2010 to $2013 .{ }^{\dagger}$ Mann-Whitney test; ${ }^{\ddagger} X^{2}$ test. IQR Interquartile range

Secondary objective: The effect of having discussed family planning with a physician on IBD-specific reproductive knowledge Among the respondents, $62.1 \%$ (154 of 248) reported having discussed family planning with a physician (Table 1). As shown in Table 2, women who had discussed family planning with a physician had a median CCPKnow score that was 4.0 units higher than the median CCPKnow score of those who had not (8.0 [IQR 5.0 to 11.0 ] versus 4.0 [IQR 2.0 to 8.0], respectively; $\mathrm{P}<0.001$ ). In addition, as shown in Table 2, women who discussed family planning with their gastroenterologist had a median CCPKnow score that was 5.0 points higher than the median CCPKnow score of those who had not discussed family planning with any physician, and 3.0 points higher than that of those who had discussed family planning with a nongastroenterologist only $(\mathrm{P}<0.001)$. Conversely, the proportion with poor CCPKnow scores was $36.7 \%$ higher among women who had not discussed family planning with any physician, and 32.9\% higher among women who had discussed family planning with a nongastroenterologist only, compared with the proportion with poor CCPKnow scores among women who had discussed family planning with their gastroenterologist (65 of 94 [69.1\%] versus 32 of 49 [65.3\%] versus 34 of 105 [32.4\%]; $\mathrm{P}<0.001)$.

As shown in Table 5, multivariable logistic regression estimated an OR adjusted for current age and marital status of 0.44 (95\% CI 0.25 to 0.77 ) for the effect of having discussed family planning with a physician on having a poor CCPKnow score; thus, discussion of family planning with a physician corresponded to $56 \%$ lower odds of having a poor CCPKnow score. Table 5 also shows that discussion of family planning with a gastroenterologist corresponded to $72 \%$ lower odds of having a poor CCPKnow score, while discussion with a nongastroenterologist did not show any effect.

Given that there were large differences in the prevalence of childlessness across groups defined according age and marital status, the logistic regression model was repeated within strata of age and marital status. Table 6 shows that the observed inverse association between discussion of family planning and having a poor CCPKnow score was strongest among women $>34$ years of age. In contrast, discussion of family planning was not clearly associated with the CCPKnow score in women $\leq 34$ years of age (there were too few single women $>34$ years of age to examine this relationship in this group). 
TABLE 3

Multivariable logistic regression model for estimating the effect of inflammatory bowel disease (IBD)-specific reproductive knowledge* on childlessness

\begin{tabular}{|c|c|c|}
\hline & OR & $95 \% \mathrm{Cl}$ \\
\hline \multicolumn{3}{|l|}{ All respondents } \\
\hline CCPKnow score, per unit increase & 0.92 & $0.86-0.99$ \\
\hline \multicolumn{3}{|l|}{ Marital status } \\
\hline Single $(n=62)$ & 1.0 & - \\
\hline Partnered $^{\dagger}(n=181)$ & 0.21 & $0.08-0.53$ \\
\hline Current age, per year increase & 0.86 & $0.82-0.91$ \\
\hline \multicolumn{3}{|l|}{ Women $\leq 34$ years of age } \\
\hline CCPKnow score, per unit increase & 0.88 & $0.79-0.97$ \\
\hline \multicolumn{3}{|l|}{ Marital status } \\
\hline Single $(n=62)$ & 1.0 & - \\
\hline Partnered $(n=91)$ & 0.17 & $0.051-0.56$ \\
\hline Current age, per year increase & 0.80 & $0.71-0.90$ \\
\hline \multicolumn{3}{|l|}{ Women $>34$ years of age } \\
\hline CCPKnow score, per unit increase & 0.99 & $0.88-1.1$ \\
\hline \multicolumn{3}{|l|}{ Marital status } \\
\hline Single $(n=5)$ & 1.0 & - \\
\hline Partnered $(n=88)$ & 0.52 & $0.078-3.5$ \\
\hline Current age, per year increase & 0.96 & $0.83-1.1$ \\
\hline \multicolumn{3}{|c|}{ Women $\leq 34$ years of age AND partnered } \\
\hline CCPKnow score, per unit increase & 0.87 & $0.78-0.98$ \\
\hline Current age, per year increase & 0.81 & $0.70-0.91$ \\
\hline \multicolumn{3}{|c|}{ Women $>34$ years of age AND partnered } \\
\hline CCPKnow score, per unit increase & 0.98 & $0.86-1.1$ \\
\hline Current age, per year increase & 0.99 & $0.83-1.1$ \\
\hline \multicolumn{3}{|c|}{ Women $\leq 34$ years of age AND single $\ddagger$} \\
\hline CCPKnow score, per unit increase & 0.92 & $0.70-1.2$ \\
\hline Current age, per year increase & 0.78 & $0.60-1.0$ \\
\hline
\end{tabular}

Analysis stratified according to age and marital status among 248 female IBD patients from the IBD Consultation and Research Clinic, University of Alberta Hospital (Edmonton, Alberta), 2010 to 2013. *According to Crohn's and Colitis Pregnancy Knowledge survey [CCPKnow] score; †Partnered includes married/ long-term relationship and divorced; $¥$ Unable to complete for women $>34$ years of age who are single because $n=5$

Secondary objective: The effect of discussion of family planning with a physician on childlessness, voluntary childlessness and trying to become pregnant

There was a difference in the prevalence of childlessness across groups based on discussion of family planning (Table 2) because 59.6\% (56 of 94) of those who had not discussed family planning with a physician were childless, compared with $41.0 \%$ (43 of 105) of these who had discussed family planning with their gastroenterologist, and 59.2\% (29 of 49) of those who had discussed family planning with a nongastroenterologist $(\mathrm{P}=0.016)$.

Among the 116 childless women who responded to the question on their decisions regarding having children, the prevalence of voluntary childlessness was similar among those who had discussed family planning with a physician and those who had not discussed family planning with a physician (eight of 67 [11.9\%] versus seven of 49 [14.3\%]; $\mathrm{P}=0.71$ ). As shown in Table 4, multivariable logistic regression estimated an OR adjusted for current age and marital status of 0.28 (95\% CI 0.057 to 1.3 ) for the effect of having discussed family planning with a gastroenterologist on voluntary childlessness among childless women. Thus, discussion of family planning with a gastroenterologist corresponded with $72 \%$ lower odds of voluntary childlessness among childless women. However, due to small numbers, the wide CI leaves uncertainty regarding the direction of this effect. Multivariable logistic
TABLE 4

Multivariable logistic regression model for estimating the effect of infalmmatory bowel disease (IBD)-specific reproductive knowledge* and having discussed family planning with a physician on voluntary childlessness and on trying to become pregnant

\begin{tabular}{lcc}
\hline Variable & OR & $\mathbf{9 5 \%} \mathbf{C l}$ \\
\hline Effect of CCPKnow on voluntary childlessness & & \\
CCPKnow score & 0.91 & $0.79-1.0$ \\
Current age, years & 1.2 & $1.1-1.3$ \\
Marital status & & \\
$\quad$ Single & 1.0 & - \\
Partnered $^{\dagger}$ & 1.2 & $0.27-5.2$ \\
\hline
\end{tabular}

Effect of discussion of family planning on voluntary childlessness ${ }^{\ddagger}$ Have discussed family planning with a physician No

Gastroenterologist

Nongastroenterologist

1.0

Current age, years

0.28

0.26

$0.057-1.3$

Marital status

Single

Partnered

$.043-1.5$
$1.1-1.3$

Effect of CCPKnow on trying to become pregnant

CCPKnow score

Current age, years

1.0

1.6

$0.32-7.6$

Marital status

Single

1.2

1.1

$1.0-1.4$

Partnered

1.0

7.1

$0.81-62$

Data from 116 childless female IBD patients from the IBD Consultation and Research Clinic, University of Alberta (Edmonton, Alberta) Hospital, 2010 to 2013. *According to Crohn's and Colitis Pregnancy Knowledge survey (CCPKnow) score; †Includes married/long-term relationship and divorced; ¥Unable to complete for the effect of discussion of family planning with a physician on trying to become pregnant because all 48 women who had not discussed family planning were not trying to become pregnant

regression was not performed for the effect of discussion of family planning with a physician on trying to become pregnant because all of the 48 childless women who had not discussed family planning with a physician indicated they were not trying to become pregnant (48 of 48 [100.0\%]).

\section{DISCUSSION}

The present analysis is the largest reported study of women with IBD assessing IBD-specific reproductive knowledge and investigating relationships among IBD-specific knowledge, discussion of family planning and childlessness. Previous studies reported results from smaller numbers of respondents, or from a combination of male and female patients with IBD (3). The response rate in the present study was relatively high $(57.1 \%)$, as was the prevalence of childlessness $(51.6 \%)$ in the study population. More than one-half $(52.8 \%)$ of the participants had poor IBD-specific reproductive knowledge scores according to the CCPKnow survey; this is higher than the percentage of patients with poor knowledge $(44.8 \%)$ reported in the study by Selinger et al (14), which first used the CCPKnow survey.

The present study estimated a clear inverse dose-response gradient for the relationship of IBD-specific reproductive knowledge, as measured by the CCPKnow survey, and childlessness; that is, each one point increase in the CCPKnow score corresponded to lower odds of childlessness. Knowledge regarding reproductive issues in IBD, however, was not the only factor associated with childlessness in the present study population. Other factors associated with childlessness included current age, marital status, age at diagnosis and duration of disease. 
TABLE 5

Multivariable logistic regression model for estimating the effect of having discussed family planning with a physician on having poor inflammatory bowel disease (IBD)-specific reproductive knowledge*

\begin{tabular}{|c|c|c|}
\hline & OR & $95 \% \mathrm{Cl}$ \\
\hline \multicolumn{3}{|c|}{ Discussed family planning with any physician } \\
\hline \multicolumn{3}{|c|}{ Have discussed family planning with a physician } \\
\hline No $(n=94)$ & 1.0 & - \\
\hline Yes $(n=154)$ & 0.44 & $0.25-0.77$ \\
\hline \multicolumn{3}{|l|}{ Marital status } \\
\hline Single $(n=67)$ & 1.0 & - \\
\hline Partnered ${ }^{\dagger}(n=181)$ & 0.22 & $0.10-0.48$ \\
\hline Current age, per year increase & 1.0 & $0.98-1.1$ \\
\hline \multicolumn{3}{|c|}{ Discussed family planning with a gastroenterologist } \\
\hline \multicolumn{3}{|c|}{ Have discussed family planning with a physician } \\
\hline No $(n=94)$ & 1.0 & - \\
\hline Gastroenterologist $(n=105)$ & 0.28 & $0.15-0.53$ \\
\hline Nongastroenterologist $(n=49)$ & 1.0 & $0.48-2.2$ \\
\hline \multicolumn{3}{|l|}{ Marital status } \\
\hline Single $(n=67)$ & 1.0 & - \\
\hline Partnered ${ }^{\dagger}(n=181)$ & 0.24 & $0.11-0.52$ \\
\hline Current age, per year increase & 1.0 & $0.98-1.1$ \\
\hline
\end{tabular}

Data from 248 female IBD patients from the IBD Consultation and Research Clinic, University of Alberta Hospital (Edmonton, Alberta), 2010 to 2013. *According to Crohn's and Colitis Pregnancy Knowledge survey score;

tIncludes married/long-term relationship and divorced

\section{TABLE 6}

Multivariable logistic regression model for estimating the effect of having discussed family planning with a physician on having poor inflammatory bowel disease (IBD)-specific reproductive knowledge*

\begin{tabular}{|c|c|c|}
\hline & OR & $95 \% \mathrm{Cl}$ \\
\hline \multicolumn{3}{|l|}{ Among childless women } \\
\hline \multicolumn{3}{|c|}{ Have discussed family planning with a physician } \\
\hline No $(n=56)$ & 1.0 & - \\
\hline Gastroenterologist $(n=43)$ & 0.31 & $0.12-0.78$ \\
\hline Nongastroenterologist $(n=29)$ & 1.3 & $0.46-3.9$ \\
\hline \multicolumn{3}{|l|}{ Marital status } \\
\hline Single $(n=60)$ & 1.0 & - \\
\hline Partnered ${ }^{\dagger}(n=68)$ & 0.34 & $0.14-0.84$ \\
\hline Current age (per year increase) & 1.0 & $0.93-1.1$ \\
\hline \multicolumn{3}{|l|}{ Among women who have children } \\
\hline \multicolumn{3}{|c|}{ Have discussed family planning with a physician } \\
\hline No $(n=38)$ & 1.0 & - \\
\hline Gastroenterologist $(n=62)$ & 0.32 & $0.13-0.81$ \\
\hline Nongastroenterologist $(n=20)$ & 0.82 & $0.26-2.5$ \\
\hline \multicolumn{3}{|l|}{ Marital status } \\
\hline Single $(n=7)$ & 1.0 & - \\
\hline Partnered ${ }^{\dagger}(n=113)$ & 0.10 & $0.011-0.99$ \\
\hline Current age (per year increase) & 1.1 & $1.0-1.2$ \\
\hline \multicolumn{3}{|l|}{ Among women $\leq 34$ years of age } \\
\hline \multicolumn{3}{|c|}{ Have discussed family planning with a physician } \\
\hline No $(n=59)$ & 1.0 & - \\
\hline Gastroenterologist $(n=68)$ & 0.35 & $0.15-0.84$ \\
\hline Nongastroenterologist $(n=28)$ & 1.4 & $0.48-4.0$ \\
\hline \multicolumn{3}{|l|}{ Marital status } \\
\hline Single $(n=62)$ & 1.0 & - \\
\hline Partnered ${ }^{\dagger}(n=93)$ & 0.20 & $0.088-0.46$ \\
\hline \multirow[t]{2}{*}{ Current age (per year increase) } & 1.0 & $0.91-1.1$ \\
\hline & \multicolumn{2}{|c|}{ Continued in next columr } \\
\hline
\end{tabular}

TABLE 6 - CONTINUED

Multivariable logistic regression model for estimating the effect of having discussed family planning with a physician on having poor inflammatory bowel disease (IBD)-specific reproductive knowledge*

\begin{tabular}{|c|c|c|}
\hline & OR & $95 \% \mathrm{Cl}$ \\
\hline \multicolumn{3}{|l|}{ Among women $>34$ years of age ${ }^{\dagger}$} \\
\hline \multicolumn{3}{|c|}{ Have discussed family planning with a physician } \\
\hline No $(n=35)$ & 1.0 & - \\
\hline Gastroenterologist $(\mathrm{n}=37)$ & 0.19 & $0.063-0.57$ \\
\hline Nongastroenterologist $(n=21)$ & 0.60 & $0.18-2.0$ \\
\hline \multicolumn{3}{|l|}{ Marital status } \\
\hline Single $(n=5)$ & 1.0 & - \\
\hline Partnered $^{\dagger}(n=88)$ & 0.74 & $0.069-7.9$ \\
\hline Current age (per year increase) & 0.91 & $0.79-1.0$ \\
\hline \multicolumn{3}{|c|}{ Among women $\leq 34$ years of age AND partnered } \\
\hline \multicolumn{3}{|c|}{ Have discussed family planning with a physician } \\
\hline No $(n=23)$ & 1.0 & - \\
\hline Gastroenterologist $(n=54)$ & 0.40 & $0.13-1.2$ \\
\hline Nongastroenterologist $(n=16)$ & 1.6 & $0.4 .3-6.0$ \\
\hline Current age (per year increase) & 1.0 & $0.90-1.1$ \\
\hline \multicolumn{3}{|c|}{ Among women $>34$ years of age AND partnered } \\
\hline \multicolumn{3}{|c|}{ Have discussed family planning with a physician } \\
\hline No $(n=30)$ & 1.0 & - \\
\hline Gastroenterologist $(n=37)$ & 0.19 & $0.065-0.57$ \\
\hline Nongastroenterologist $(n=21)$ & 0.61 & $0.18-2.0$ \\
\hline Current age (per year increase) & 0.91 & $0.80-1.0$ \\
\hline \multicolumn{3}{|c|}{ Among women $\leq 34$ years of age AND single $\ddagger$} \\
\hline \multicolumn{3}{|c|}{ Have discussed family planning with a physician } \\
\hline No $(n=36)$ & 1.0 & - \\
\hline Gastroenterologist $(n=14)$ & 0.30 & $0.067-1.3$ \\
\hline Nongastroenterologist $(n=12)$ & 1.01 & $0.18-5.9$ \\
\hline Current age (per year increase) & 0.98 & $0.85-1.1$ \\
\hline
\end{tabular}

Analysis stratified according to childlessness, age and marital status among 248 female IBD patients from the IBD Consultation and Research Clinic, University of Alberta Hospital (Edmonton, Alberta), 2010 to 2013. *According to Crohn's and Colitis Pregnancy Knowledge survey score; IIncludes married/ long-term relationship and divorced; $\neq$ Unable to complete for women $>34$ years of age who are single because $n=5$

While age and marital status are inevitably strong determinants of childlessness, the goal of the present analysis was to estimate the extent to which IBD-specific reproductive knowledge is associated with childlessness among women with IBD, independent of other determinants of childlessness. Even after adjusting for the confounding effects of current age and marital status, both of which encompass a wide range of factors that affect childlessness, our results still showed an inverse effect gradient of increasing levels of IBD-specific reproductive knowledge associated with decreasing odds of childlessness. This inverse relationship was strongest among women $\leq 34$ years of age who were partnered, and was not clearly associated with childlessness in single women $\leq 34$ years of age; thus, reproductive knowledge was strongly associated with childlessness once a stable partnered relationship was established.

Although it may be theorized that women who have been pregnant and who have children may have higher IBD-specific reproductive knowledge gained through the experience of having children, this study estimated higher IBD-specific reproductive knowledge scores among women who had discussed family planning with a physician compared with women who had not done so, irrespective of whether they had children. In addition, the present study estimated that the effect of having discussed family planning with a physician is dependent on the physician type. Those who had discussed family planning with their gastroenterologist had much higher CCPKnow scores than 
those who had spoken with a nongastroenterologist only or who had not spoken with any physician. The odds of having poor CCPKnow scores were $72 \%$ lower among women who had discussed family planning with their gastroenterologist, compared with those who had not discussed family planning with any physician. The effect of discussion of family planning with a gastroenterologist on IBD-specific reproductive knowledge remained strong even after stratification according to childlessness, age and marital status. This finding is important becuase it suggests that higher IBD-specific reproductive knowledge does not necessarily require the personal experience of having children, and that discussion with a physician, especially a gastroenterologist may influence IBD-specific reproductive knowledge.

Previous studies have estimated that approximately $20 \%$ to $30 \%$ of women with IBD discuss family planning with a physician $(13,21)$, although Marri et al (1) reported that $68 \%$ of their study population had discussed reproductive issues with a physician. In this study population, $62.1 \%$ of women indicated that they previously had discussed family planning with a physician, with $42.3 \%$ indicating they had discussed family planning with their gastroenterologist.

While the cross-sectional design of the present study does not rule out the possibility that women who derive their knowledge from other sources seek family planning discussions with physicians, the results suggest the potential for improving women's IBD-specific reproductive knowledge through increasing the engagement of physicians in discussing family planning with their IBD patients. Further studies differentiating physician IBD-specific reproductive knowledge levels are required because nongastroenterologist physicians may have lower IBD-specific reproductive knowledge.

The present study also estimated the effect of IBD-specific reproductive knowledge on voluntary childlessness and trying to become pregnant among childless women with IBD. When childless women who did not want to have children were classified as having 'voluntary childlessness', the 'voluntary childlessness' rate (15 of 116 [12.9\%]) was slightly lower than reported in previous studies $(1,2,4,12)$. Higher IBD-specific reproductive knowledge did not correspond to lower odds of voluntary childlessness, but did correspond to higher odds of trying to become pregnant among childless women with IBD. Due to the cross-sectional nature of the study, however, it is unclear if childless women who were trying to become pregnant had higher CCPKnow scores due to actively seeking information because they were trying to become pregnant, or if they decided to try to become pregnant due to higher knowledge levels.

Although we had a relatively high response rate and a large number of respondents, there are several limitations to the present study. The patient population was sampled from a single tertiary care centre and, therefore, may represent a patient population that may be more knowledgeable than the general female IBD population. However, this university-based centre services a large referral base that encompasses Western Canada, and the patient population is thus, quite diverse in terms of demographic factors and IBD disease history. We attempted to obtain a representative sample of women with IBD by systematically recruiting all female IBD patients in the target age group who had been seen in the IBD clinic within the past three years regardless of their disease characteristics or reproductive history. Women who responded may have been more knowledgeable or interested in the study than those who did not respond and, thus, may not represent all women with IBD. Also, despite having a relatively large sample size compared with previous studies, results estimated for subgroups of childless women (voluntary childless; and those who were trying to become pregnant) had reduced precision. In addition, although we captured highest level of education as a marker of socioeconomic status, we did not capture financial socioeconomic status, which may have an effect on knowledge, concerns and interaction with health care providers. Nevertheless, our results show how complex this topic is, and reveal questions that warrant further research.

Another limitation of the present cross-sectional survey was its inability to establish the time sequence of events. The present study cannot determine what a woman's IBD-specific reproductive knowledge was when she made the decision to remain voluntarily childless or to have children. It is possible that women who made the decision to remain childless earlier in their lives have lower IBD-specific reproductive knowledge because they believed they did not need to seek this knowledge. Our data pattern, which shows that the women in the youngest age group (18 to 24 years) and those who were single at time of the study had the lowest median CCPKnow scores, supports this possibility. In addition, the finding that childless women who were trying to become pregnant had higher CCPKnow scores also suggests that they may have sought out the knowledge because they were trying to become pregnant.

When assessing knowledge, personal experience may play a role, and women with a history of pregnancy had higher CCPKnow scores and a lower prevalence of poor CCPKnow levels. Nevertheless, the finding that discussion of family planning with a physician, especially a gastroenterologist, corresponded to higher CCPKnow scores and lower prevalence of poor CCPKnow level knowledge suggests that regardless of personal experience, discussion with a physician is associated with better IBD-specific reproductive knowledge.

It should be noted that the study questionnaire did not capture whether the patient or a physician initiated discussions of family planning, or exactly what the discussion encompassed. Physicianpatient discussion of family planning could vary from a brief discussion about contraception or fertility, to lengthy discussions about reproductive issues in $I B D$, and are likely to vary substantially across health care providers. These would be important pieces of information to capture in future studies. However, even with this limitation, our study does indicate that a discussion of family planning, reported as such by the patient, is associated with higher knowledge scores, and identifies discussion of family planning as a potentially modifiable factor that may influence patient knowledge and childlessness. Additionally, future studies should examine whether men with IBD also have similar concerns and, thus, contribute to decisions regarding voluntary childlessness in couples in which one or both partners has IBD.

Overall, the present study found that poor IBD-specific reproductive knowledge is strongly associated with increased childlessness among women with IBD and describes an association of increasing IBD-specific reproductive knowledge with decreasing odds of childlessness. A potentially modifiable factor that was associated with better knowledge and lower odds of childlessness among women with IBD was discussion of family planning with a physician, specifically with a gastroenterologist. Future research investigating this topic should focus on elucidating the complex factors involved in voluntary childlessness among women with IBD, and on identifying effective approaches for physicians who care for women with IBD to discuss family planning issues specific to their concerns.

ACKNOWLEDGEMENTS: Vivian Huang was supported to perform this research by the Alberta Innovates Health Solutions (AIHS) Clinician Research Fellowship Award. Additional support for the research was provided by the Alberta Inflammatory Bowel Disease Consortium, the Centre of Excellence for Gastrointestinal Inflammation and Immunity Research (CEGIIR), and the Cecile Mactaggart Summer Studentship. RNF acts as the article guarantor and contributed to the study design, data collection, data analysis, and manuscript drafting and editing. VH contributed to study design, data collection, data analysis, and manuscript drafting and editing. HJC contributed to data analysis and manuscript editing. KIK contributed to study design, data collection and manuscript editing. KG contributed to study design, data analysis and manuscript editing. $\mathrm{KH}$ and LAD contributed to study design and manuscript editing. All authors approved the final version of the manuscript.

DISCLOSURES: The authors have no financial disclosures or conflicts of interest to declare. 


\section{REFERENCES}

1. Marri SR, Ahn C, Buchman AL. Voluntary childlessness is increased in women with inflammatory bowel disease. Inflamm Bowel Dis 2007;13:591-9.

2. Mountifield R, Bampton P, Prosser R, et al. Fear and fertility in inflammatory bowel disease: A mismatch of perception and reality affects family planning decisions. Inflamm Bowel Dis 2009;15:720-5.

3. Tavernier N, Fumery M, Peyrin-Biroulet L, et al. Systematic review: Fertility in non-surgically treated inflammatory bowel disease. Aliment Pharmacol Ther 2013:38:847-53.

4. Mountifield RE, Prosser R, Bampton P, et al. Pregnancy and IBD treatment: This challenging interplay from a patients' perspective. J Crohns Colitis 2010;4:175-82.

5. Willoughby CP, Truelove C. Ulcerative colitis and pregnancy. Gut 1980;21:469-74.

6. Mayberry JF, Weterman IT. European survey of fertility and pregnancy in women with Crohn's disease: A case control study by European collaborative group. Gut 1986;27:821-5.

7. Khosla R, Willoughby CP, Jewell DP. Crohn's disease and pregnancy. Gut 1984;25:52-6.

8. Lindhagen T, Bohe M, Ekelund G, et al. Fertility and outcome of pregnancy in patients operated on for Crohn's disease. Int J Colorectal Dis 1986;1:25-7.

9. Dr Domabl FT, Burton IL, Goligher JC. Crohn's disease and pregnancy. BMJ 1972;3:550-3.
10. Hudson M, Flett G, Sinclair TS, et al. Fertility and pregnancy in inflammatory bowel disease. Int J Gynecol Obstet 1997;58:229-37.

11. Manosa M, Navarro-Llavat M, Marin L, et al. Fecundity, pregnancy outcomes, and breastfeeding in patients with inflammatory bowel disease: A large cohort survey. Scan J Gastroenterol 2013;48:427-32.

12. Selinger CP, Eaden J, Selby W, et al. Inflammatory bowel disease and pregnancy: Lack of knowledge is associated with negative views. J Crohns Colitis 2013;7:e206-213.

13. Toomey D, Waldron B. Family planning and inflammatory bowel disease: The patient and the practitioner. Fam Pract 2013;30:64-8.

14. Selinger CP, Eaden J, Selby W, et al. Patients' knowledge of pregnancy-related issues in inflammatory bowel disease and validation of a novel assessment tool ('CCPKnow'). Aliment Pharmacol Ther 2012;36:57-63.

15. Gawron LM, Hammond C, Keefer L. Documentation of reproductive health counseling and contraception in women with inflammatory bowel diseases. Patient Educ Counsel 2014;94:134-7.

16. Julsgaard M, Norgaard M, Hvas CL, et al. Self-reported adherence to medical treatment prior to and during pregnancy among women with ulcerative colitis. Inflamm Bowel Dis 2011;17:1573-80. 


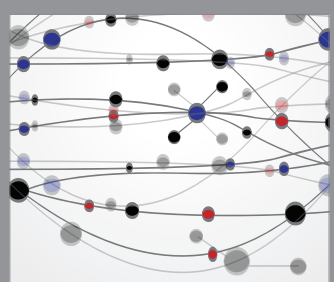

The Scientific World Journal
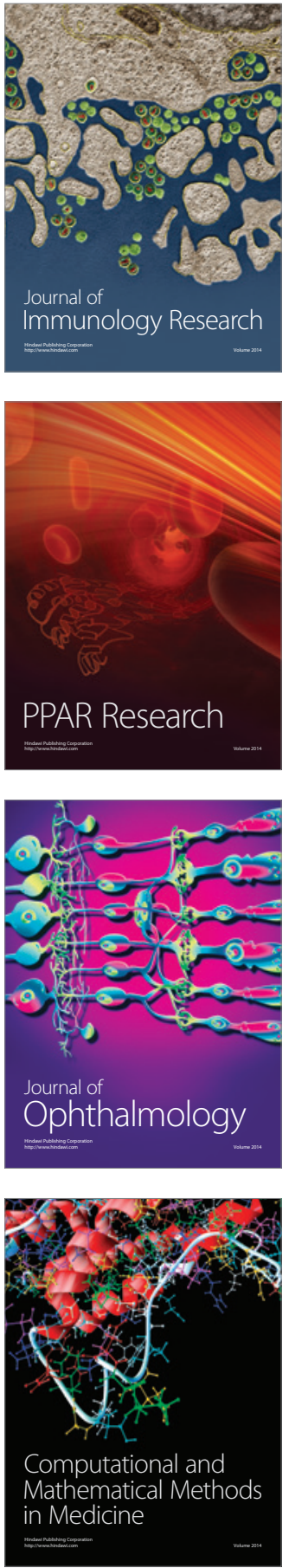

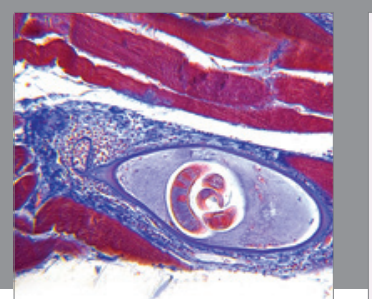

Gastroenterology Research and Practice

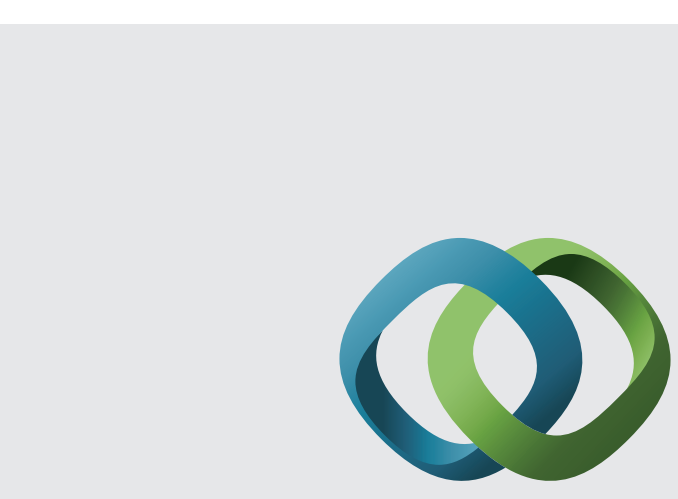

\section{Hindawi}

Submit your manuscripts at

http://www.hindawi.com
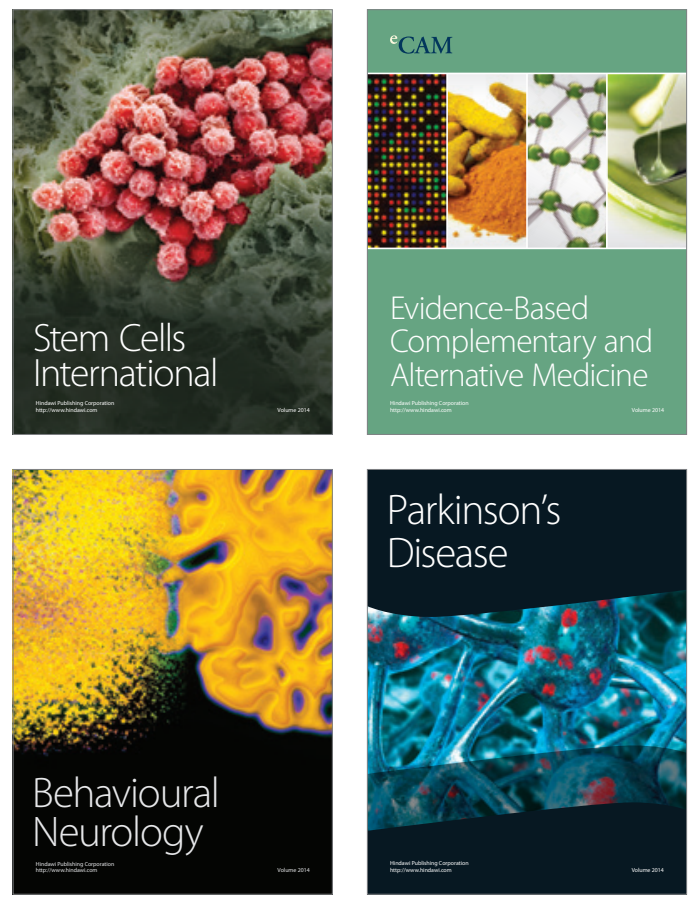
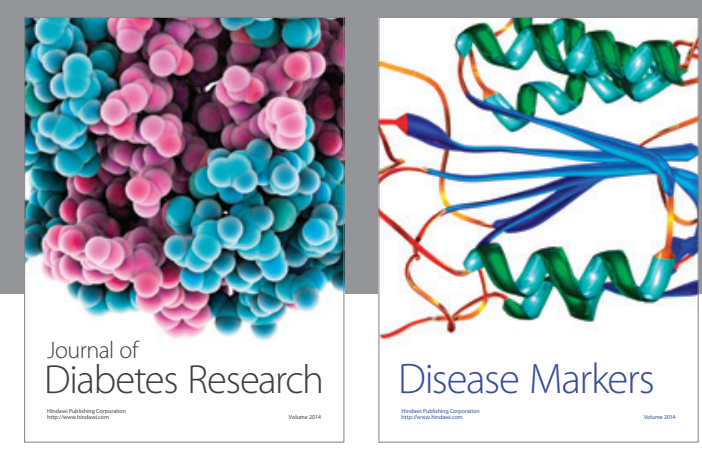

Disease Markers
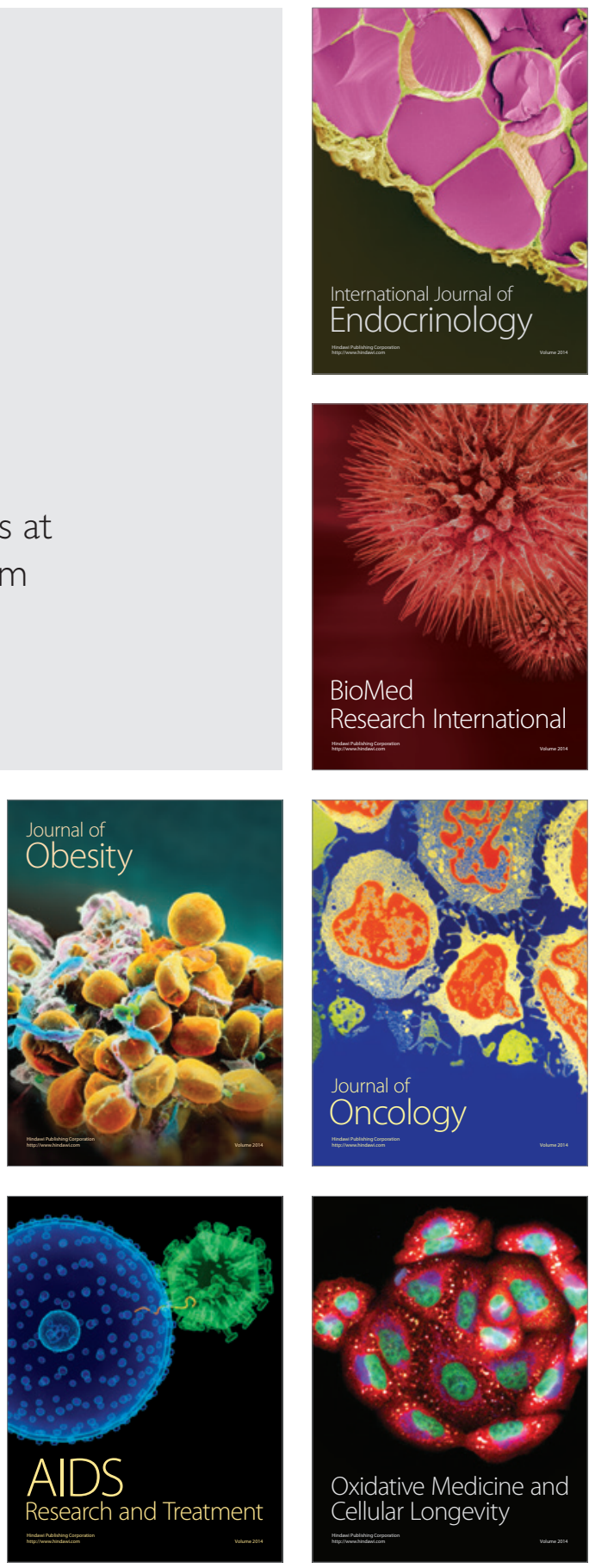